\title{
Percepções das deformidades dentofaciais: do bem-estar psíquico à indicação de cirurgia
}

\author{
Jorge Faber*, Ana Paula Megale Hecksher Faber**
}

Percepções do paciente quanto ao tratamento com cirurgia ortognática, bem-estar e status psicológico e psiquiátrico: um revisão sistemática

Clínicos que atuam no atendimento de portadores de deformidades dentofaciais frequentemente fazem menção a certo sofrimento, por parte dos pacientes, causado pela deformidade. E um assunto recorrente sobre o tema é se, e o quanto, podemos auxiliar aqueles que se submetem a tratamento a ter melhor qualidade de vida. Com o intuito de melhor entender essa questão, autores finlandeses realizaram uma revisão sistemática de estudos que abordavam o bem-estar psicológico de pacientes ortodôntico-cirúrgicos ${ }^{1}$. Foram avaliados artigos em inglês publicados entre 2001 e 2009 nas bases de dados PubMed, Web of Science e PsycInfo. O processo de análise dos trabalhos foi realizado por dois investigadores, e eles excluíram aqueles que versavam sobre questões metodológicas, com pacientes fissurados ou sindrômicos, expansão maxilar cirurgicamente assistida ou bloqueio intermaxilar. As referências de todos os trabalhos de revisão foram vasculhadas manualmente, com a intenção de resgatar novos artigos para o estudo em questão. Trinta e cinco artigos preencheram os critérios de seleção e foram incluídos na revisão. Os motivos principais para buscar tratamento foram as melhoras na autoconfiança, aparência e função oral. $\mathrm{O}$ tratamento resultou em melhora no bem-estar relatada pelos pacientes, ainda que essa melhora não tenha sido identificada com métodos atuais de avaliação dessa questão. As mudanças no bem-estar foram, em geral, identificadas com desenhos de estudo desenvolvidos para analisar o impacto da saúde oral na qualidade de vida, por exemplo, questionário para qualidade de vida para cirurgia ortognática e de impacto na saúde oral. As principais conclusões do estudo foram que, em geral, os pacientes não vivenciam problemas psiquiátricos relacionados à deformidade dentofacial. Entretanto, subgrupos de pacientes podem passar por problemas, como a ansiedade ou a depressão. Uma dificuldade em relação à análise desses pacientes decorre do fato da maioria dos estudos comparar médias de grupos de pacientes tratados a controles e/ou normas populacionais. $\mathrm{Ou}$ seja, não há estratificação ou análise de covariáveis que possam influenciar no resultado das variáveis amostradas. Esse é um campo fértil para novos estudos, em especial estudos prospectivos que tratem das alterações diárias do humor e bem-estar.

Pacientes cirúrgicos de Classe II e III são menos felizes com a aparência facial e dentária do que indivíduos controle

Comumente se aceita que os principais benefícios da cirurgia ortognática são psicossociais em sua natureza, e que a maioria dos pacientes que busca tratamento o faz devido à sua insatisfação com a estética dentofacial. Existe um número relativamente restrito de trabalhos que analisem a autopercepção da atratividade facial entre pacientes de cirurgia ortognática. Exatamente para preencher essa lacuna, um estudo da Irlanda avaliou se a autopercepção da atratividade dentária e facial de pacientes que requeriam cirurgia ortognática diferia ou não de indivíduos controle ${ }^{2}$.

A satisfação com a aparência dentária e facial foi avaliada por meio de questionários. Eles foram

\footnotetext{
* Editor-chefe do Dental Press Journal of Orthodontics. Doutor em Biologia-Morfologia pelo Laboratório de Microscopia Eletrônica/UnB. Mestre em Ortodontia e Ortopedia Facial pela UFRJ.

** Médica, Psiquiatra, Mestre em Ciências da Saúde-Medicina do Sono, com clínica privada de Psiquiatria em Brasília/DF, Brasil.
} 
respondidos por 162 pacientes que necessitavam de tratamento ortodôntico-cirúrgico e 157 pacientes controle. Foram coletadas variáveis obtidas com escalas analógicas visuais, respostas binárias e abertas. Os dados foram analisados por diferentes métodos estatísticos. Os pacientes de cirurgia ortognática, em especial os de Classe II, eram menos felizes com seus dentes e sua face do que os indivíduos controle. Dentro dos pacientes de cirurgia ortognática, os pacientes de Classe III e as mulheres, em geral, eram mais propensos a ter olhado sua face de perfil, para criticar sua aparência. Uma maior proporção de pacientes Classe II, do que de pacientes Classe III, desejariam mudar sua aparência; e, quanto mais velhas as pessoas eram, mesmo entre os pacientes controle, mais insatisfeitas estavam com sua aparência facial.

Esses dados são importantes para se entender a percepção do paciente quanto ao problema que possui. Isso é especialmente relevante com a crescente preocupação em centrar os tratamentos nos anseios do paciente. Ainda há espaço para se analisar o desconforto físico e o sofrimento psíquico daqueles que se submetem ao preparo ortodôntico para cirurgia.

\section{A percepção de necessidade de tratamento} com cirurgia ortognática varia de acordo com a posição anteroposterior da mandíbula

Um interessante estudo foi realizado por pesquisadores brasileiros para identificar a possível associação entre a posição anteroposterior da mandíbula e a percepção de necessidade de cirurgia ortognática por ortodontistas, cirurgiões bucomaxilofaciais, artistas e leigos ${ }^{3}$. Para tanto, quatro fotografias de adultos de ambos os sexos, dois negros e dois brancos, foram alteradas digitalmente. As alterações de cada fotografia produziram sete fotos: uma com perfil reto, três com crescentes intensidades de retrusão mandibular, e três com crescentes intensidades de protrusão mandibular. Assim, as 28 fotografias foram analisadas pelo painel de avaliadores, e foi solicitado que respondessem quais faces necessitariam de cirurgia ortognática para tornar o perfil mais atrativo, e se eles próprios buscariam a cirurgia se o perfil daquela face fosse o seu próprio. Os resultados mostraram que, quanto maior era a discrepância, independentemente do sentido da alteração ser para Classe II ou III, maior era a tendência de todos os avaliadores indicarem a cirurgia e se manifestarem mais propensos a operar se aquele perfil fosse o seu. Além disso, as faces de mulheres Classe III foram mais indicadas para a cirurgia do que as de Classe II. Por outro lado, homens Classe II receberam mais indicação de cirurgia do que os Classe III. Quando os avaliadores foram solicitados a responder se fariam ou não a cirurgia se aquele perfil fosse o seu, as fotografias de mulheres tiveram mais respostas afirmativas do que as dos homens. Talvez isso se reflita na conhecida maior prevalência de mulheres buscando cirurgia ortognática do que homens.

Quando o fator avaliador foi analisado, leigos foram menos propensos e cirurgiões bucomaxilofaciais foram mais propensos a indicar a cirurgia do que os demais grupos. Um resultado especialmente interessante é que os examinadores, em geral, manifestaram uma diferença significativa entre as indicações de cirurgia para as faces, caso os perfis fossem seus ou não; quando os perfis eram hipoteticamente dos avaliadores, eles foram menos propensos a indicar a cirurgia do que se os perfis fossem de outra pessoa. Não houve diferença significativa entre as indicações de cirurgia de negros e brancos.

\section{REFERÊNCIAS}

1. Alanko OM, Svedström-Oristo AL, Tuomisto MT. Patients' perceptions of orthognathic treatment, well-being, and psychological or psychiatric status: a systematic review. Acta Odontol Scand. 2010 May 31. [Epub ahead of print].

2. Johnston C, Hunt O, Burden D, Stevenson M, Hepper P. Self-perception of dentofacial attractiveness among patients requiring orthognathic surgery. Angle Orthod. 2010 Mar;80(2):361-6.

3. Almeida MD, Bittencourt MAV. Anteroposterior position of mandible and perceived need for orthognathic surgery. J Oral Maxillofac Surg. 2009 Jan;67(1):73-82.

\section{Endereço para correspondência} Jorge Faber

Brasília Shopping Torre Sul sala 408

CEP: 70.715-900 - Brasília/DF

E-mail: faber@dentalpress.com.br 